\title{
Successful Myomectomy with Pregnancy
}

\author{
$\mathrm{K} \mathrm{KHAN}^{\mathrm{a}}$, K FATEMA ${ }^{\mathrm{b}}$, MB ASHRAF ${ }^{c}$, NEA PATUARY $^{\mathrm{d}}$, H HALDAR $^{\mathrm{e}}$
}

\begin{abstract}
:
The prevalence of Leiomyomas with pregnancy is reported as $0.3-2.9 \%$.They usually remain asymptomatic during pregnancy, if they are small.In symptomatic one, management is generally expectant and surgical removal is particularly delayed until after delivery. Symptomatic myoma, which does not respond to conservative management need antenatal myomectomy. Second trimester is preferable for its better outcome $e^{8,12}$.We present a case of symptomatic multiple uterine fibroids which include a huge one, diagnosed during pregnancy clinically \& ultrasonography
\end{abstract}

\section{Introduction:}

The leiomyoma or myoma, also known as fibroid is the commonest of all pelvic tumors, being present in $40 \%-60 \%$ in the reproductive age group \& half of these women will be symptomatic in their life time ${ }^{2}$. The etiology still remains unclear. The hypothesis is that; origin is monoclonal-simulating the parent cell $^{3}$.It is composed essentially of muscle tissue with a variable amounts of fibrous connective tissue. Number of leiomyomas vary from 01-200and are frequently multiple. They are hard in consistency except by degeneration when they become firm to hard in consistency. they aresurrounded bypseudocapsule which consists of compressed normal uterine wall.Their cut surface show whorled and white appearance ${ }^{4}$. Leiomyomas have been reported as a sole cause in about $2.4 \%$ cases of subfertility ${ }^{5}$. Many women with myomas succeed in

a. Kohinoor Khan - Professor of Obstetrics \& Gynecology department at Gonoshasthaya Samaj Vittik Medical College \& Hospital, Savar, Dhaka - 1344.

b. Kaniz Fatema - Registrar of Obstetrics \& Gynecology department.

c. Manabi Binte Ashraf - Medical Officer, Obstetrics \& Gynecology.

d. Noor - E - AlamPatuary - Professor of Anesthesiology.

e. Harbilash Haldar - Assistant Professor of Anesthesiology.

Address of Correspondence: Dr. Kohinoor Khan - Professor of Obstetrics \& Gynecology department at Gonoshasthaya Samaj Vittik Medical College \& Hospital, Savar, Dhaka - 1344.

Received: 17 October, 2018

Accepted: 01 September, 2020 confirmed it. The casewas managed successfully by antenatal myomectomy due to failure of conservative management.Totalweight of fibroids was $1500 \mathrm{gms}$. The pregnancy progressed to term uneventfully \& elective caesarian section was done on 28/04/2019 for transverse lie. A healthy female baby weighing $03 \mathrm{Kg}$ was delivered. The patient was discharged in good condition on 05/05/2019.

Key Notes: Fibromyoma, myomectomy, red degeneration, abruptio placentae, premature rupture of membrane, pretermlabour, obstructed labour.

(J Bangladesh Coll Phys Surg 2021; 39: 59-61)

DOI: https://doi.org/10.3329/jbcps.v39i1.50460

becoming pregnant. Pain is the most common symptom of fibroids, in second and third trimester of pregnancy, if they are large. This process is called "red degeneration". Abortion, Preterm delivery, abruptio placentae, premature rupture of membrane, obstructed labour are other complications of fibroids with pregnancy.To avoid such complications, we sometimes attempt myomectomy with pregnancy in selected patients.

Case Presentation: Mrs. X, 26 years old primigravida presented with abdominal swelling, amenorrhoea for 10 weeks, severe lower abdominal pain \& incomplete voiding of urine for one week. She is married for four years $\&$ has one and half a year history of primary subfertility. Two years back she was diagnosed as a case of multiple uterine fibroidsconfirmedby ultrasonography\& underwent myomectomy. The patient looked flushed $\&$ had very much discomfort, difficulties in respiration. She was normotensive \& had mild pyrexia, respiratory rate was 24 breaths/min. Her abdomen was grossly distended, measured about $30 \mathrm{~cm}$ from the symphysis pubis, firm in consistency, irregular surface on palpation. Sonographic examination showed an intrauterine alive fetus about 11 weeks' gestation, a huge myoma of about $18 \mathrm{~cm} \times 17 \mathrm{~cm}$ size, also showed different sizes of myomas all over the surface of the uterus. She was managed conservatively but after three weeks of conservative management, she got admitted into GonosasthayaSamajVittik Medical college\& Hospital with intractable pain \& retention of urine. 
Her all routine investigations including serum electrolytes \& creatinine were within normal limits. Her blood group was B (+ve), $\mathrm{Hb} \%$ was $10.6 \mathrm{gm} / \mathrm{dl}$. Myomectomy was done at 14 weeks of gestation.

Preoperative counselling was given to both the patient \& her party about the operation \& an informed written consent was taken for the risk of operation also.

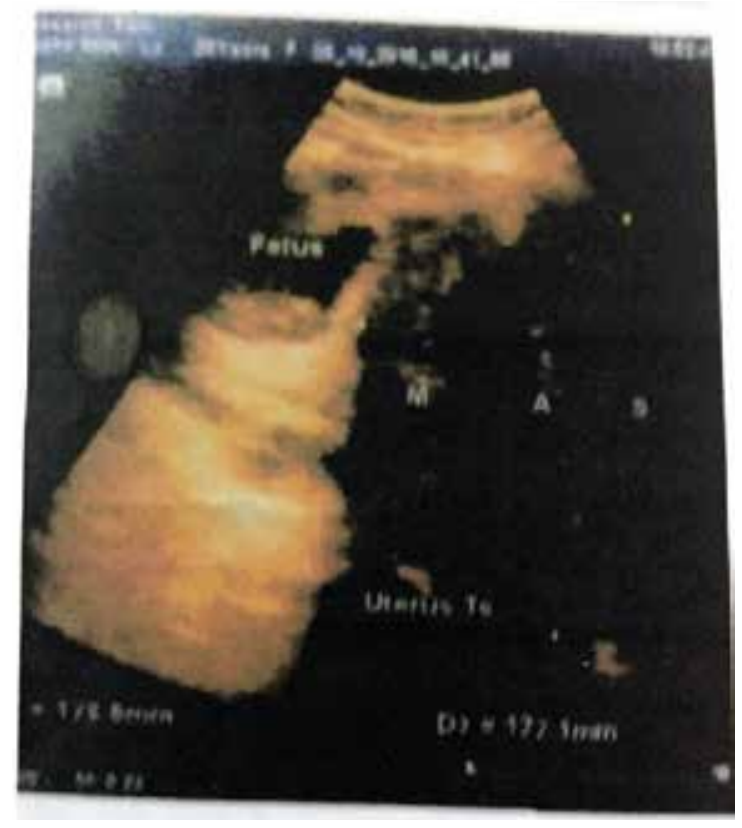

Foetus at 14 weeks before myomectomy

Operation was done under spinal anesthesia. Abdomen was opened through midline subumbilical incision removing the previous scar. Four medium sized myomas measuring about $5 \mathrm{~cm} \times 6 \mathrm{~cm}$ were removed from lower part of anterior uterine wall. The larger one, $(18 \mathrm{~cm} \times 17 \mathrm{~cm})$ in size was at the upper part of anterior uterine wall, intramural in nature \& was removed by gentle enucleation; the base wasclosed by catgut ' 0 ' (ethicon). Precaution was maintained not to disturb the gestational sac. She lost near about 01 liters of blood \& received 03 units of whole human blood per- operatively. The weight of the larger fibroid was about $1000 \mathrm{gm} \mathrm{\&} \mathrm{the} \mathrm{total} \mathrm{weight} \mathrm{of} \mathrm{the}$ rest four fibroidswas about $500 \mathrm{gm}$. Section from the grossly enucleated fibroid was histologically confirmed as leiomyoma with necrobiosis.Her post-operative period was uneventful. She received injection Hydroxy Progesterone Caproate intramuscularly $(250 \mathrm{mg})$ two ampoules every third day for one month \& tablet allylestrenol(5mg) per oral three times daily up to 28 weeks with her regular tonics. Tab. Paracetamol $(500 \mathrm{mg})$ per oral two or three times daily if necessary for pain were prescribed. Her operation area looked healthy. Stitches were removed on $10^{\text {th }}$ post-operative day. $\mathrm{Hb} \%$ was $10.8 \mathrm{gm} / \mathrm{dl}$ on $07^{\text {th }}$ post-operative day. Repeat ultrasonography on $10^{\text {th }}$ post-operative day showed normally growing fetus of about 16 weeks of gestation. She was discharged on $14^{\text {th }}$ post-operative day in good condition.

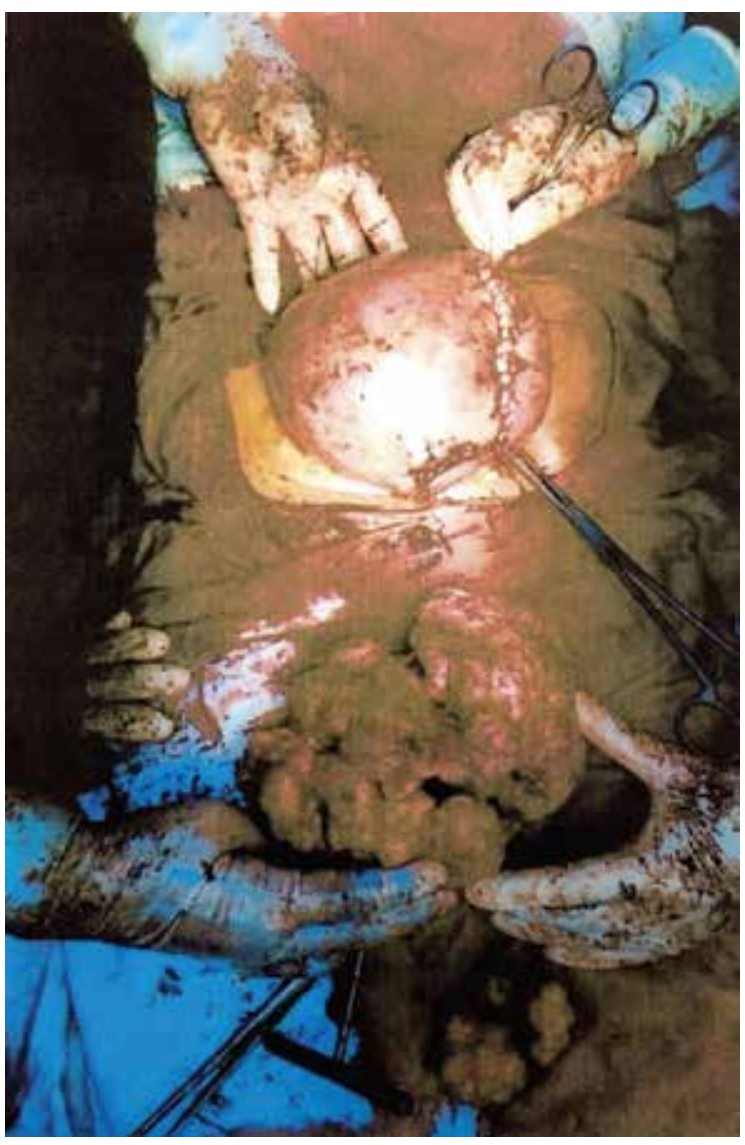

After Myomectomy

\section{Follow up:}

The patient was advised to attened gynae out patient department every two weeklyupto $28^{\text {th }}$ weeks, then every weekly until delivery. Each time she was asked for any complain \&her vital signs including pulse, blood pressure, temperature $\&$ respiratory rate was recorded. Any sign of anaemia, jaundice\&oedema were noted. Uterine fundal height was recorded in cm.Every month $\mathrm{Hb} \%$, routine\& microscopic examination of urine; random blood sugar at $28^{\text {th }}$ weeks of gestation were done. Anomally scan of 
fetus was recorded at $26^{\text {th }}$ weeks of gestation. Fetal movement $\&$ fetal heart beats are important signs of fetal wellbeing.At 38 weeks of gestationTransverse Lie, an abnormal presentation was detected clinically \& ultrasonography confirmedit. Pregnancy was terminated by lower uterine caesarean section.

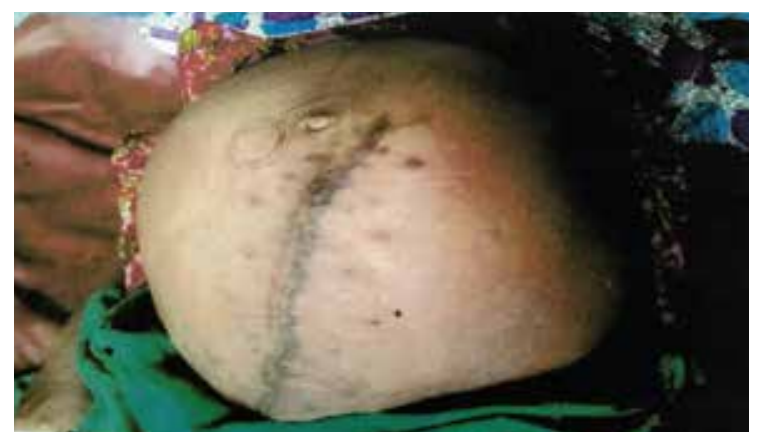

At term pregnancy with previous scar on abdomen

Her intraoperative \& postnatal period was also uneventful. Blood transfusion was not required during \& after operation.The Pediatrician attended\& clinically examined the female baby and found no deformity in her body. The patient was discharged on $8^{\text {th }}$ post -operativeday. Subsequent check-up after 07 \& 42 days of discharge was advised.

\section{Discussion:}

Surgical intervention was done due to rapid increase in lesion size causing discomfort \& severe abdominal pain, retention of urine, not responding to conservative management with bed rest, hydration, analgesic, non-steroidal anti-inflammatory \& tocolytic drugs medication.Myomas often enlarge during pregnancy as myoma cells contain more estrogen receptors ${ }^{6}$.The most common complication specially in $2^{\text {nd }}$ trimester is the syndrome of painful myoma,due to red or carneous degeneration\& occurs in $5-8 \%$ of myomas in pregnancy ${ }^{7}$. Its association with recurrent pregnancy loss is observed ${ }^{9}$.Complications in $3^{\text {rd }}$ trimester are premature rupture of membrane, preterm labour,abnormal presentation, increase caesarean section rate.During pregnancy increased vascularity and abnormal uterine action, women are at increased risk of per-operative \& post-operative bleeding with morbidity. Surgery if indicated, caesarean myomectomy can be done successfully that time ${ }^{10}$.

Risk of recurrence \& persistence of fibroids in abdominal myomectomy in nongravid uterus is about $30 \%-50 \%$, risk of relaparotomy is about $20 \%-25 \%$, following myomectomy, patients should have a mandatory hospital delivery, although the chance of scar rupture is $\operatorname{rare}^{11}$.During L.U.C.S nakedeyeexamination of uterus showed smooth surface of the uterus without any scar of previous myomectomy.Enucleated tumor with cut section showed dark areas revealing raw beef appearance often containing cystic spaces. The odor is often fishy due to fatty acids. Color is due to the presence of haemolysedred cells \&haemoglobin. Microscopically, evidences of necrosis are present. Vessels are thrombosed but extravasation of blood is unlikely. Partial recovery is possible as such called "necrobiosis."

\section{Conclusion:}

Myomectomy is a riskier operation, when the fibroid(s) is too big or too many, more when cavity is open.Myomectomy in this patient provided reassurance.So surgical management with uterine leiomyoma with pregnancy may be successfully performed in carefully selected patients.

\section{References:}

1. ChisaraUmezurike and Paul Feyi-Waboso Successful myomectomy during pregnancy: A case report, Human Reproduction, Bio Med Central, Published Date: 16.08.2005. https://doi.org/ 10.1186/ 1742-4755-2-6, PMid:16105174 PMCid:PMC1198256

$2,3,4,6,11$.

HiralalKonar - DC Dutta's Textbook of Gynecology. 8th Edition. Benign Lesions of the Uterus. Page: $224,227,233$.

5. Verkauf BS. Myomectomy for fertility enhancement \& preservation. Fertilsteril1992;58:1-15, https:// doi.org/ 10.1016/S0015-0282(16)55128-0

7. Pratab Kumar, Narendra Malhotra. Jeffcoate's Principles of Gynaecology. 8thEdition, Volume:49, Page: 723- 725,898.

8. MN Shafiee, Mi Norazlin\&Arifuddin - A successful antenatal Myomectomy, Malays Fam Physician.2012; 7 (2-3). Published online 2012, Aug 31.

9. Coutinho EM, Mala HS. The contractile response of the human uterus, fallopian tubes \& ovary to prostaglandins in vivo. FertilSteril 1971;58:1-15.

10. AhikariSudhbir, Goswami Sebanti - Cesarean Myomectomy, J ObstetGynecol India Vol. 56, No. 6: November/December 2006, Page: 486- 488.

12. Lavinia Domenia,Caccette\& P. DenudettePanieci. Laparotomic Myomectomy at 16th weeks of Pregnancy: a case report, case report in Obstetrics \&Gynaecology, Vol. 2014. Article ID: 154348. 